\title{
Determining mineralogy, size, and number concentration of individual aeolian nano- and micro- dust particles measured by single particle- ICPMS in East Antarctic ice during the last climatic cycle
}

MADELEINE C LOMAX-VOGT ${ }^{1}$, OLESIK JOHN ${ }^{1}$, COLE BRADLEY $^{1}$, AJA ELLIS ${ }^{1}$, JULIA SHEETS ${ }^{1}$, SUSAN WELCH $^{1}$, GARRET BLAND ${ }^{2}$, LUKE MONROE ${ }^{2}$, RYAN SULLIVAN $^{2}$ AND PAOLO GABRIELLI ${ }^{1}$

${ }^{1}$ The Ohio State University

${ }^{2}$ Carnegie Mellon University

Presenting Author: lomax-vogt.2@osu.edu

The number concentration and elemental chemical composition of individual atmospheric nano-and micro- dust particles affect the Earth's climate, directly by reflecting, scattering, or absorbing solar radiation; and indirectly by acting as ice and cloud condensation nuclei. Previous measurements of the size and elemental composition of particles entrapped in Antarctic ice have been limited by conventionally used instrumentation. Coulter counter determines particle size, but only for particles larger than about $0.5 \mu \mathrm{m}$. The average bulk elemental composition of many particles has been obtained by dissolving the particles and measuring the resulting solution by inductively coupled plasma mass spectrometry (ICP-MS). We used single particle ICP-Time of Flight MS to measure a complete elemental mass spectrum from each of thousands of individual nano- and micro-particles entrapped in horizontal ice sections from Taylor Glacier (coastal East Antarctica) spanning part of the last climatic cycle $(9,000-44,000$ years BP). The elemental composition and mass of each measured particle was used to infer mineralogy and to estimate particle size. Our initial goal is to establish if and how aeolian dust sources and transport through the atmosphere have changed over time. Ultimately, our measurements will provide a more comprehensive estimate of the mineralogy, size, and possible atmospheric concentration of aeolian dust over past time. These data could be used to improve climate model accuracy by incorporating the chemical and physical properties of aeolian particles into simulations. 